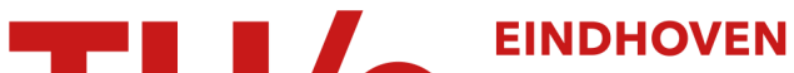 \\ UNIVERSITY OF \\ TECHNOLOGY
}

\section{Identification and parameter-varying decoupling of a 3-DOF platform with manipulator}

\section{Citation for published version (APA):}

Gajdusek, M., Damen, A. A. H., \& Bosch, van den, P. P. J. (2008). Identification and parameter-varying decoupling of a 3-DOF platform with manipulator. In International Symposium on Power Electronics, Electrical Drives, Automation and Motion, 2008 : SPEEDAM 2008 ; Ischia, 11 - 13 June 2008 (pp. 691-696). Institute of Electrical and Electronics Engineers. https://doi.org/10.1109/SPEEDHAM.2008.4581104

DOI:

10.1109/SPEEDHAM.2008.4581104

Document status and date:

Published: 01/01/2008

\section{Document Version:}

Publisher's PDF, also known as Version of Record (includes final page, issue and volume numbers)

\section{Please check the document version of this publication:}

- A submitted manuscript is the version of the article upon submission and before peer-review. There can be important differences between the submitted version and the official published version of record. People interested in the research are advised to contact the author for the final version of the publication, or visit the $\mathrm{DOI}$ to the publisher's website.

- The final author version and the galley proof are versions of the publication after peer review.

- The final published version features the final layout of the paper including the volume, issue and page numbers.

Link to publication

\section{General rights}

Copyright and moral rights for the publications made accessible in the public portal are retained by the authors and/or other copyright owners and it is a condition of accessing publications that users recognise and abide by the legal requirements associated with these rights.

- Users may download and print one copy of any publication from the public portal for the purpose of private study or research.

- You may not further distribute the material or use it for any profit-making activity or commercial gain

- You may freely distribute the URL identifying the publication in the public portal.

If the publication is distributed under the terms of Article 25fa of the Dutch Copyright Act, indicated by the "Taverne" license above, please follow below link for the End User Agreement:

www.tue.nl/taverne

Take down policy

If you believe that this document breaches copyright please contact us at:

openaccess@tue.nl

providing details and we will investigate your claim. 


\title{
Identification and Parameter-varying Decoupling of a 3-DOF Platform with Manipulator
}

\author{
M. Gajdusek, A.A.H. Damen, and P.P.J. van den Bosch \\ Eindhoven University of Technology, Den Dolech 2, Eindhoven, (The Netherlands)
}

\begin{abstract}
The paper describes identification and a new parameter-varying decoupling method for a 3-degree-offreedom (DOF) platform with a manipulator on top of it, which is magnetically levitated by 9 voice-coil actuators. The identification has been performed in closed-loop using two different indirect approaches. In the first approach timedomain data of the system were processed using Ho-Kalman algorithm. The second approach was based on frequencyresponse measurements. The 3 DOFs of the platform are coupled and the coupling is even varying as the manipulator on top is moving. In order to design separate SISO controllers for each DOF of the platform, a new decoupling method has been developed which uses frequency response measurements of the system obtained for different positions of the manipulator.
\end{abstract}

Index Terms -- Decoupling of systems. Identification, MIMO systems, Parameter-varying systems

\section{INTRODUCTION}

In lithography industry or for pick-and-place machines there is a tendency to increase precision of production at high speeds. In lithography industry wafers are processed with precision in nanometer scale, but the position must be changed very fast to reduce processing time. These two requirements lead to design of a new generation of vibration-free manipulators based on magnetic levitation and propulsion. Such manipulators can work in vacuum and if we combine such a magnetically levitated and propelled planar actuator with a precise manipulator on top of it, we can achieve a high-precision, high-speed, vibration-free manipulator. Control of magnetically levitated contactless planar actuator with 6 DOFs is itself difficult task (e.g. [1], [2], and [3]). An even bigger challenge is to control such a planar actuator with an added manipulator on top of it. The manipulator causes disturbing forces and torques acting on the platform. Precise control of the planar actuator is necessary, because platform will be lifted and operate just about 1 $\mathrm{mm}$ or less above the surface. Such a working condition is a trade off between operational height and power needed to lift the platform with the manipulator in the final prototype. In order to facilitate control design of the platform a broad-banded decoupling of the multiple-input multiple-output transfers is indispensable.

The goal of this paper is to describe the identification

This IOP-EMVT project is funded by SenterNovem. SenterNovem is an agency of the Dutch Ministry of Economical Affairs. of our experimental setup and a new parameter-varying decoupling method. The experimental setup is a 3degree-of-freedom (DOF) platform with a manipulator on top which was build as a pre-prototype of a fully 6-DOF planar actuator with a manipulator on top. The purpose of the 3-DOF setup is to test rejection of the disturbances caused by the manipulator on the levitating platform.

In the final 6-DOF prototype, levitation and propulsion will be provided with coils in standstill base-plate together with permanent magnets in the platform [1]. The manipulator on the platform will be wirelessly controlled and powered [4]. Such wireless system allows for combination of long-stroke movement of the platform with precise short-stroke movement of the manipulator (Fig. 1).

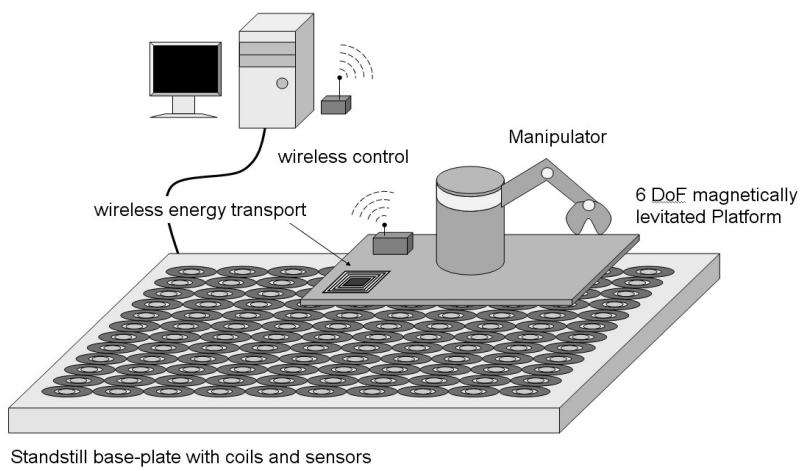

Fig. 1. Concept of 6-DOF magnetically levitated platform with manipulator.

In order to test and validate control design for the final contactless planar actuator with manipulator, an experimental setup has been designed, which yields only 3 DOFs for the platform [5].

The 3 DOFs of the platform are coupled and the coupling is even varying as the manipulator on top is moving. With the intention to design separate SISO controller for each DOF of the platform, we have developed a new decoupling method which does not need model of the system. Instead, just frequency response functions (FRF) of the system measured for different positions of the manipulator are required.

The paper is organized as follows: The experimental setup is described in section II. Description and the results of the identification procedure are presented in section III. In section IV, decoupling procedure is explained and the experimental results are presented in section $\mathrm{V}$. 


\section{EXPERIMENTAL SETUP}

The experimental setup consists of two main parts: a 3-DOF platform levitated and actuated by 9 voice coils and 2-DOF manipulator on top of it (Fig. 2).

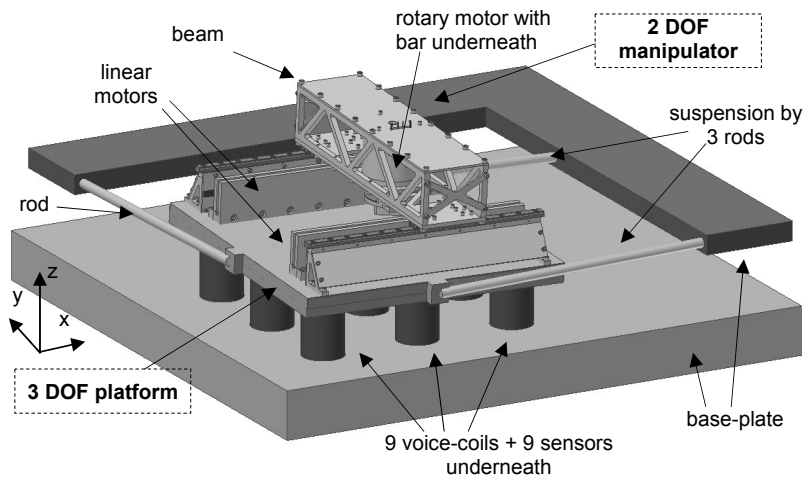

Fig. 2. Drawing of the experimental setup.

The platform, that mimics the final magnetic array, is suspended such that it can only move in 3 DOFs: vertically and over two tilting angles. The other 3 DOFs are fixed by a suspension system consisting of 3 rods connecting the platform with the base-plate. Because the final planar actuator will be magnetically levitated and controlled in 6 DOFs in vacuum, it will have zero spring constants and zero damping. Therefore the suspension system was designed in a way to achieve minimal spring constants and minimal damping in 3 DOFs as well, but with very high stiffness in other 3 DOFs. We have chosen the option with built-in leaf-springs at the ends of the rods. The rods can easily bend in two directions at its ends but they cannot shrink or extend, so they behave as a spring with low spring constant in two directions and with high spring constant elsewhere.

The platform is actuated by 9 voice coils underneath which are distributed into regular array to simulate the topology of the final planar actuator and is used for gravity compensation and for manipulator platform control in 3 DOFs. Using this over-actuated platform allows us also to distribute necessary force for lifting the platform as well as to control disturbances from the manipulator. Because of the actuators shape, voice coils also behave as air dampers.

Furthermore inductive position sensors are mounted under each voice coil in such a way that we have measurement at the same position as the actuator acts (Fig. 3).

The manipulator on top of the platform is the same as the one used in final setup. It is essentially an H-bridge with the rotary motor on the beam. For high stiffness of the manipulator the following design has been chosen. The manipulator consists of two parallel three-phase linear motors with encoders which are connected by stiff beam. In the middle of the beam is a synchronous threephase rotary motor with encoder (Fig. 4) and small bar is connected to the rotary motor. Together the 3 motors provide precise linear and rotary movement of an end tip of the manipulator.

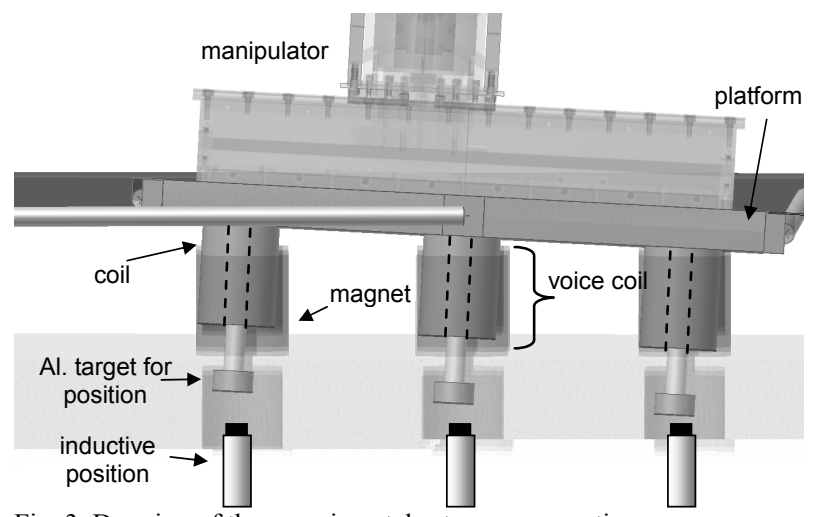

Fig. 3. Drawing of the experimental setup; cross-section.

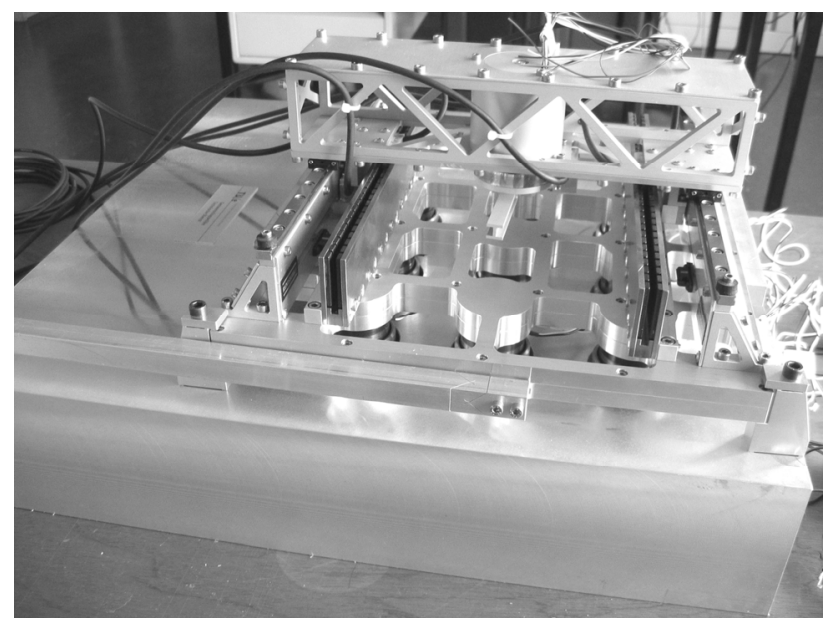

Fig. 4. Photo of the experimental setup.

\section{IDENTIFICATION}

In this section, identification procedure of the platform transfer functions will be shown.

With the force/torque inputs $\left(F_{\mathrm{z}}, T_{\psi}, T_{\theta}\right)$ and the position/orientation outputs $(z, \psi, \theta)$, the platform is expected to be a second-order mass-spring-damping system in each DOF.

The platform is designed as an almost meta-stable system (ideally double integration in each DOF) and, therefore, identification should be performed on a closedloop system. There have been developed many different methods for closed-loop identification in the past. Classical methods are e.g. joint input-output identification (e.g. [6], [7]), instrumental variable ([8], [9]) or direct identification ([10], [11]). Recently developed methods are for example two-stage [12] or dual-Youla parameterization (e.g. [13]). We have chosen classical indirect method for closed-loop identification, see (e.g. [14], [15]), because the plant itself is nearly unstable and the controller transfer functions are known as well as the excitation signal.

Identification of the closed-loop system has been done using two different indirect approaches. In the first approach time-domain data of the system were processed using Ho-Kalman algorithm [16]. The second approach was based on frequency-domain system identification, where data were obtained from the system using signal and system analyzer SigLab.

A controller, consisting of three separate SISO PI 
controllers, has been used to stabilize the system. So the three DOFs are controlled separately. The integrative components have been used to remove steady-state errors.

Because the transfer functions of the platform are influenced by state of the manipulator, the position/orientation of the manipulator beam/bar were treated as parameters of the platform. During the tests was found that only the beam of the manipulator has significant influence on the platform. Hence for each identification method, the identification was performed for three different positions of the beam (three different values of the parameter): most left, middle and most right (respectively L, M and R in Fig. 5).

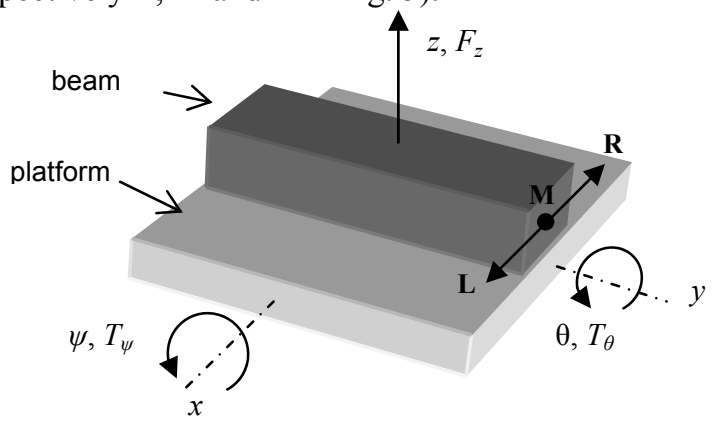

Fig. 5. Three degrees of freedom of the platform and three positions of the beam (Left, Middle and Right)

\section{A. First approach}

In the first approach of closed-loop identification, transfer function $\mathbf{G}$ from $\underline{v}$ to $\underline{y}$ has been identified (see Fig. 6). Gaussian white noise has been applied as a disturbance $\underline{v}$ each time in turn at one of the inputs of the planar actuator. All 3 outputs $y$ of the planar actuator have been measured to obtain direct- and cross-transfer functions of $\mathbf{G}=\mathbf{P}(\mathbf{I}+\mathbf{C P})^{-1}$, where $\mathbf{P}$ is the plant (platform) and $\mathbf{C}$ is controller.

From the measured time-domain data, crosscorrelation functions from the each input to the each output have been derived. Identified pulse response sequence was used in Ho-Kalman algorithm [16] as the sequence of Markov parameters of the system.

Reconstructed state-space model consists of states which are common for whole MIMO model. Because the measured data are not exact, it is necessary to reduce order of the model by choosing number of relevant singular values. From magnitude of the singular values (Fig. 7) we have verified that the identified model $\mathbf{G}_{n}$ has 9 main states, which corresponds to 6 states of the platform with 3 states of the controller. Now we want to reconstruct plant transfer functions $\mathbf{P}_{n}$ from estimate $\mathbf{G}_{n}$, by solving the equation $\mathbf{G}_{n}=\mathbf{P}_{n}\left(\mathbf{I}+\mathbf{C} \mathbf{P}_{n}\right)^{-1}$. An exact solution of $\mathbf{P}_{n}$ follows by taking

$$
\mathbf{P}_{n}=\mathbf{G}_{n}\left(\mathbf{I}-\mathbf{C G}_{n}\right)^{-1},
$$

which can be calculated as the controller $\mathbf{C}$ is known. Bode magnitude plot of the FRF of the identified plant $\mathbf{P}_{n}$ is shown in Fig. 8.

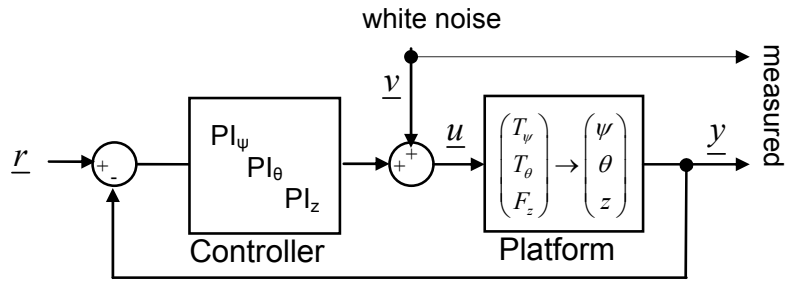

Fig. 6. The closed-loop system with applied white noise

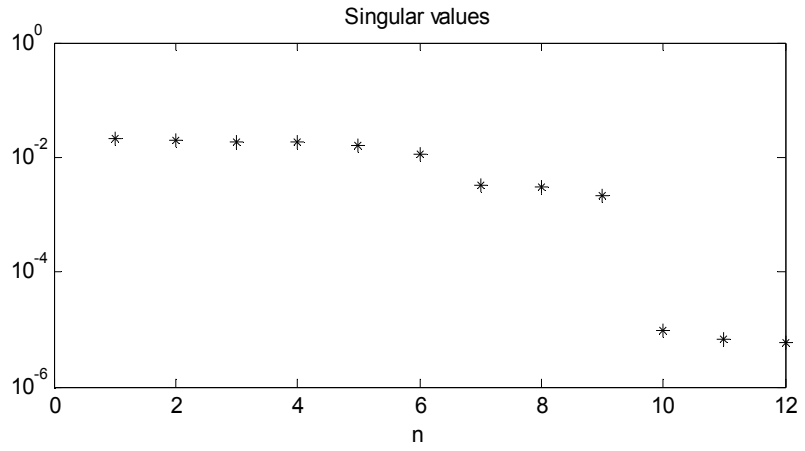

Fig. 7. Largest 12 singular values of the system

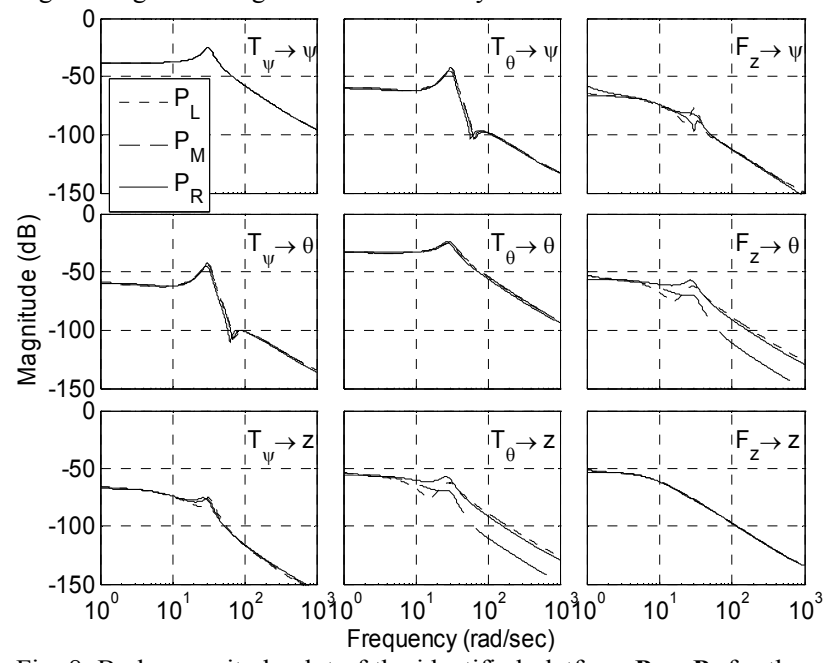

Fig. 8. Bode magnitude plot of the identified platform $\mathbf{P}_{n}=\mathbf{P}_{6}$ for three positions of the beam $\left(\mathrm{P}_{\text {Left }}, \mathrm{P}_{\text {Middle }}, \mathrm{P}_{\text {Right }}\right)$

\section{B. Second approach}

In the second approach, frequency-domain data were obtained from the system using signal and system analyzer SigLab (from Spectral Dynamics, Inc.). As a source, Gaussian white noise was used again, but the frequency response of the input sensitivity $\hat{\mathbf{S}}(j \omega)=(\mathbf{I}+\mathbf{C}(j \omega) \hat{\mathbf{P}}(j \omega))^{-1}$ was identified by correlating inserted white noise $\underline{v}$ and input $\underline{u}$ of the plant $\hat{\mathbf{P}}(j \omega)$ (Fig. 9). The frequency response of the plant can be reconstructed as follows:

$$
\hat{\mathbf{P}}(j \omega)=\mathbf{C}^{-1}(j \omega)(\hat{\mathbf{S}}(j \omega)-\mathbf{I})^{-1} .
$$

Sensitivity matrix $\hat{\mathbf{S}}(j \omega)$ is constructed out of $3 \times 3$ responses of the system and $\mathbf{C}(j \omega)$ is diagonal matrix containing 3 SISO PI controllers. Bode magnitude plot of the frequency response of the identified plant $\hat{\mathbf{P}}(j \omega)$ for the left, middle and right position of the beam is shown in Fig. 10. 


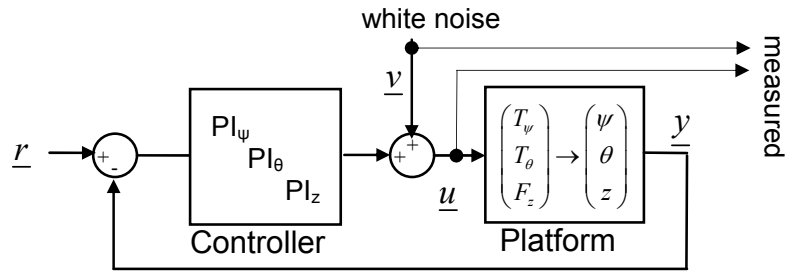

Fig. 9. The closed-loop system with applied white noise; measured with SigLab

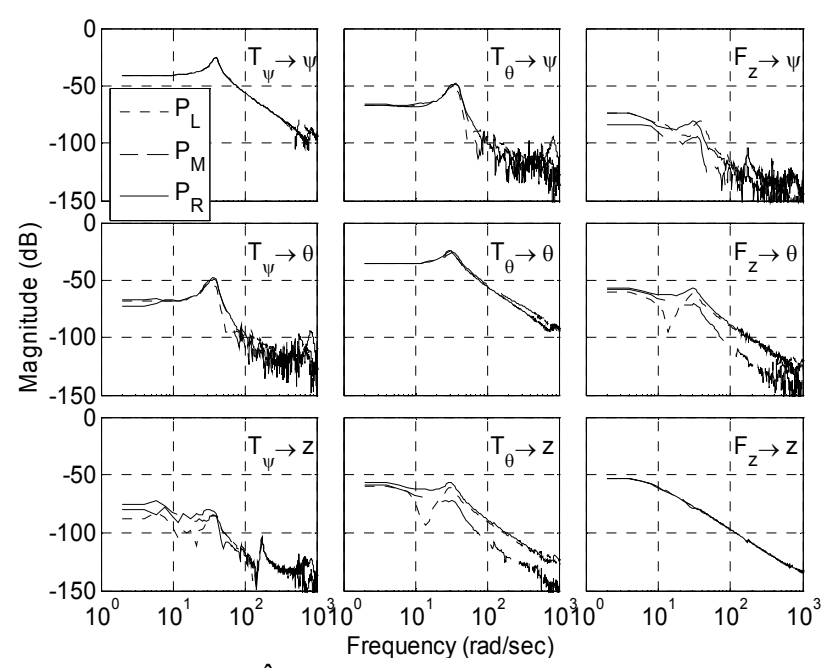

Fig. 10. FRF plot of $\hat{\mathbf{P}}(j \omega)$ identified with SigLab; three positions of the beam $\left(\mathrm{P}_{\text {Left }}, \mathrm{P}_{\text {Middle }}, \mathrm{P}_{\text {Right }}\right)$

As you can see from the Fig. 8 and 10, the results obtained by both identification techniques are similar up to frequency of approx. $400 \mathrm{rad} / \mathrm{s}$. The peaks in higher frequencies are caused by non-rigid modes and hysteresis in the bearings of the beam. These peaks are not visible in Fig. 8 (the first approach) for two main reasons: First, we limited the number of singular values of the identified system. Second, transfer function $\mathbf{G}$ from $\underline{v}$ to $y$ was measured instead of from $\underline{v}$ to $\underline{u}$ as in the second case. Hence the plant behaved as a second-order low-pass filter itself and, therefore, high frequency behavior was suppressed to the magnitude of the sensors noise.

The direct identified terms are diagonal dominant and can be easily described by the second-order model as expected, but the cross-transfer functions are unpleasant and caused by asymmetry of the setup. One part of the asymmetry is caused by suspension system because only one suspending rod is used on rotational $y$-axis (angle $\theta$ ) (see Fig. 2 and 5). Another part of the asymmetry is caused by change of the position of the manipulators beam. Both are visible on the frequency responses $T_{\theta} \rightarrow z$ and $F_{z} \rightarrow \theta$ (see Fig. 7 and 9). The other minor offdiagonal transfer functions are caused by mechanical tolerances. To reject these cross-terms, decoupling of the system has been made.

\section{DeCOUPling Procedure}

The decoupling is based on modification of Dyadic Transfer function Matrices (DTM) method presented in [17]. A $p \times p$ transfer function matrix $\mathbf{P}(s)$ is dyadic, if there exist constant $p \times p$ matrices $\mathbf{T}_{\mathrm{U}}$ and $\mathbf{T}_{\mathrm{Y}}$ and rational transfer functions $g_{1}(s), \cdots g_{p}(s)$ such that

$\mathbf{P}(s)=\mathbf{T}_{\mathrm{Y}} \operatorname{diag}\left\{g_{1}(s), \cdots g_{p}(s)\right\} \mathbf{T}_{\mathrm{U}}$.

The transformation matrices can be found based on eigenvalue ([18], [19]) or singular value [20] decomposition. Then the decoupled system is calculated as

$\mathbf{D}(s)=\mathbf{T}_{\mathrm{Y}}^{-1} \mathbf{P}(s) \mathbf{T}_{\mathrm{U}}^{-1}$.

The decoupling will be exact only for completely dyadic systems, which means that the system must have very high symmetry. There are not many systems which are dyadic. Also our system is not exactly dyadic, even when it was meant to be symmetric and controlled independently in each DOF. This means that there will still be off-diagonal elements after application of decoupling procedure $\left(\mathbf{D}_{i j, i \neq j}(s) \neq 0\right)$. Nevertheless, these elements will be reduced because of sufficient symmetry demonstrated by diagonal dominance in the system. This is shown in Fig. 11, where Relative Gain Array (RGA) measure [21] is used to show interaction between different inputs and outputs of the system identified by the second approach for the left position of the beam. If the coupling (interaction) between particular input and output is strong, the value is close to one. From the figure it is clear that the system $\mathbf{P}$ has a strong diagonal dominance and, therefore, the off-diagonal elements of $\mathbf{D}$ are significantly reduced. This is mostly visible on the plots of $T_{\theta} \rightarrow z$ and $F_{z} \rightarrow \theta$ which show coupling index of 0.3 before and 0.025 after application of DTM procedure. It is also visible that other off-diagonal elements were already small and even more reduced after DTM procedure.
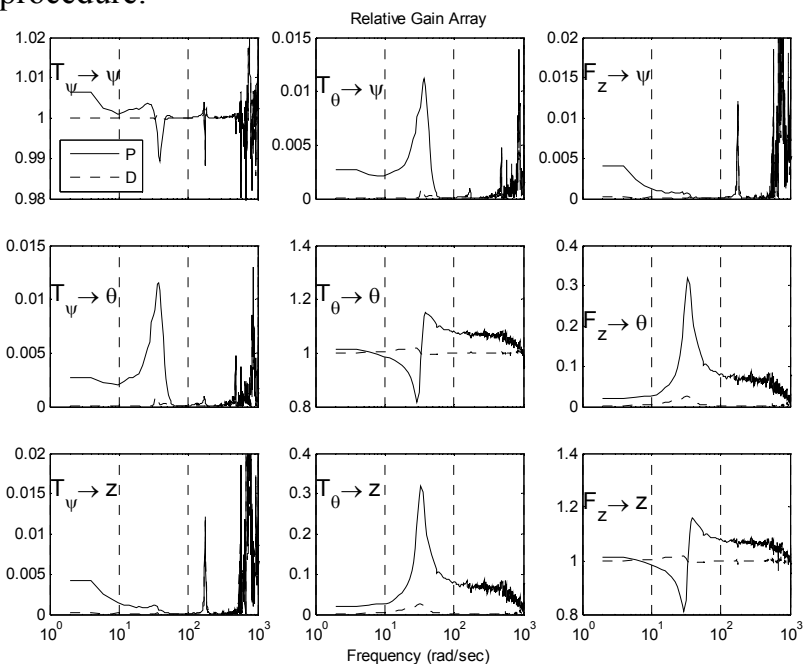

Fig. 11. RGA graphs of the original system and decoupled by DTM for left position of the beam

Due to changes in the transfer functions of the system during movement of the manipulator, decoupling based of DTM-method gives the best result just for the one position of the manipulator where the decoupling was calculated. Therefore we have improved DTM-method to achieve optimal decoupling at each position of the beam. 
The modification we have developed is based on computation of DTM at several beam positions. For other positions of the beam, transformation matrices are obtained by interpolation. We get parameter-varying transformation matrices. The complete procedure contains these steps:

1. Measurement of FRF of the system for several significant positions of the beam (values of the parameter $p$ ).

2. Application of DTM procedure with resulting $\mathbf{T}_{\mathrm{U}}(p)$ and $\mathbf{T}_{\mathrm{Y}}(p)$ matrices for each measured value of the parameter $p$.

3. Application of interpolation for other values of the parameter.

An improvement of performance can be seen in Fig. 12 , where RGA of the system (with the beam at the left position) without decoupling, decoupled with constant DTM (obtained at the middle position of the beam) and variable DTM are compared.
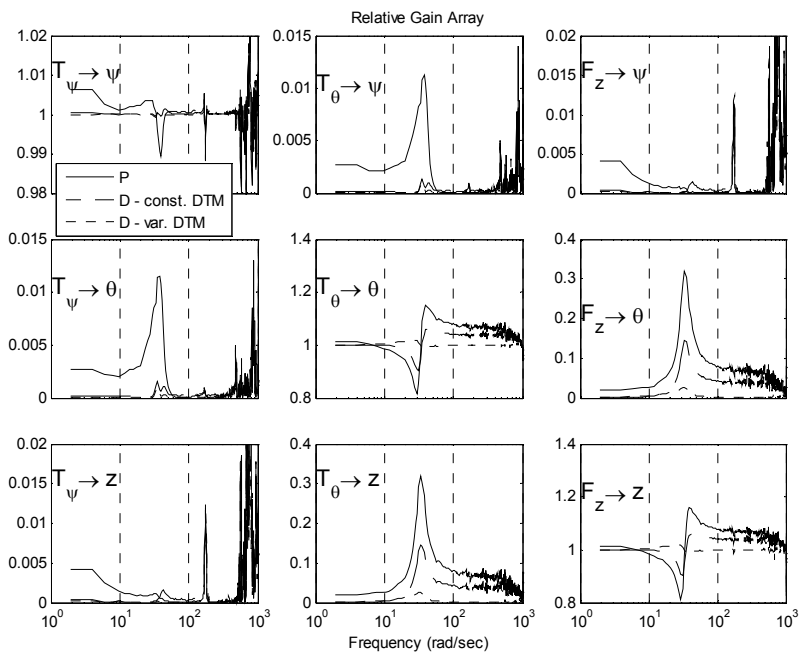

Fig. 12. RGA plots of the original system $\mathbf{P}$, the system decoupled by the constant and position dependent DTM, respectively.

It is clear, that fast change of the parameter (beam position) can influence stability of parameter-varying system. It is not straightforward how to define stability condition for our system. Fortunately, from the measured and identified FRF, the only influenced diagonal transfer function is for orientation about $y$-axis $\left(T_{\theta} \rightarrow \theta\right)$, but the change is so small, that the variation will be within stability margins of the applied controller (see Fig. 8 and 10). The parameter variation significantly influences just off-diagonal transfer functions which were even more reduced using our decoupling procedure (Fig. 13). Hence the stability will increases rather than reduces.

As the result, independent SISO controller can be designed for each DOF. Because the system is not exactly dyadic, there are still off-diagonal terms after transformation, but the transformation matrices significantly reduce the influence of the cross terms.

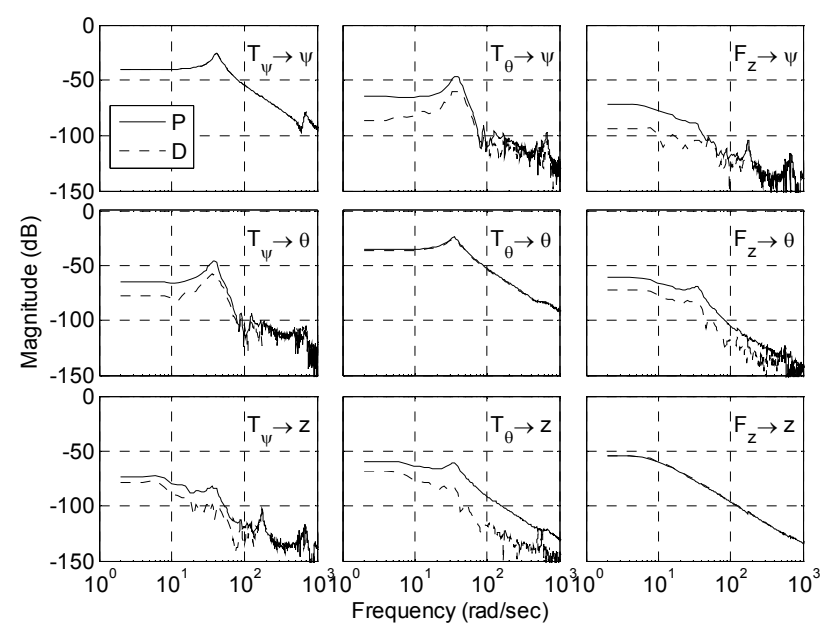

Fig. 13. FRF plots of the original system $\mathbf{P}$ and the decoupled system $\mathbf{D}$; suppression of the off-diagonal elements; for clarity only for left position of the beam.

\section{REsults}

Results of an experiment executed with moving beam of the manipulator are shown in Fig. 14. During the experiment different conditions were tested: platform without decoupling, decoupled with constant DTM and parameter-variable DTM. Time domain plot of displacement of the platform along the $z$-axis, as one of the degrees of freedom, is shown for these three different conditions. In all cases, feed forward control was used to compensate for the forces produced by movement of the manipulator and gravity force. The residual position and orientation errors of the platform were eliminated by three separate SISO PD controllers. Hence the dynamic movement of the manipulator was compensated. Still, change of the mass distribution on the platform influenced the control of the platform as you can see. Without any decoupling, variation in $z$-direction was about $50 \mu \mathrm{m}$. Constant DTM already significantly reduced the variation to about $10 \mu \mathrm{m}$. But when the parametervariable DTM was applied, the error was finally reduced to $5 \mu \mathrm{m}$. Totally, the variance was reduced 10 times. Thereby the method was proved to be working. The results on the other DOFs of the platform were less visible, because the output from the sensors was on the noise level already with the constant decoupling.

\section{CONCLUSIONS}

Project and experimental setup of 3-DOF planar actuator with manipulator has been described in this paper. Two identification techniques have been used to identify the system. Both techniques give us very close results. Identified cross-terms were be used for better decoupling of the system. Improved method for decoupling the system using parameter-varying decoupling matrices has been presented. The method gives better results for our system with the moving beam than the method with constant transformation matrices. As the result, independent SISO controllers can be then designed for the decoupled system. 

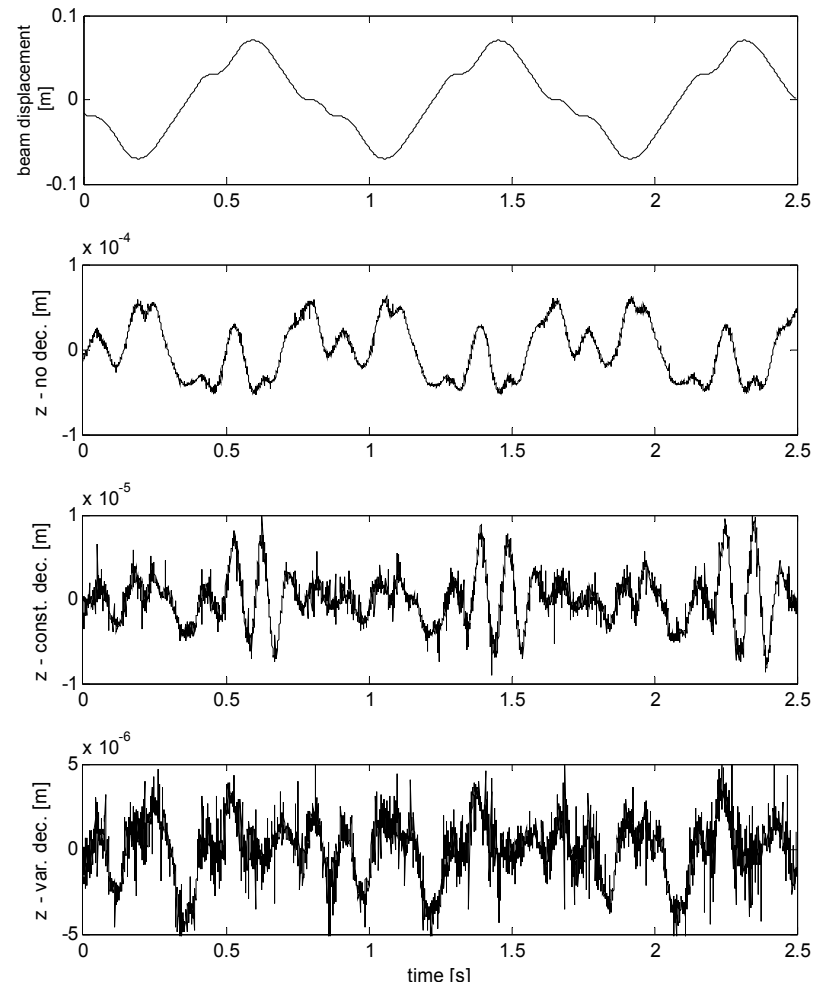

Fig. 14.Time domain plots of the influence of the decoupling on the $z$ axis while the beam is moving. Plots: position of the beam; $z$-axis without decoupling, with constant decoupling and with variable decoupling

\section{REFERENCES}

[1] van Lierop, C.M.M.; Jansen, J.W.; Damen, A.A.H.; van den Bosch, P.P.J.: Control of multi-degree-of-freedom planar actuators. Proc. IEEE Int. Symp. on Control Applications - Munich (Germany), 2006, pp. 2516-2521.

[2] Ueda, Y.; Osaki, H.: Positioning characteristics of a coreless surface motor using halbach permanent magnet array. Proc. Power Conversion Conf. 2007 - Nagoya (Japan), 2007, pp. 614-621.

[3] Compter, J.C.: Electro-dynamic planar motor. Precision Engineering, Vol. 28, 2004, pp. 171-180.

[4] de Boeij, J.; Lomonova, E; Vandenput, A.: Contactless Energy Transfer to a Moving Load Part I\&II. Proc. IEEE Int. Symp. on Industrial Electronics - Montreal (Canada), 2006, pp. 739-750.

[5] Gajdusek, M.; de Boeij, J.; Damen, A.A.H.; van den Bosch, P.P.J.: Contactless planar actuator with manipulator - Experimental setup for control. Proc. 6th Int. Symp. on Linear Drives for Industrial Applications - Lille (France), 2007, pp. 57-58.
[6] Ng, T.S.; Goodwin, G.C.; Anderson, B.D.O.: Identifiability of MIMO linear dynamic systems operating in closed loop. Automatica, vol. 13, 1977, pp. 477-485.

[7] Söderström, T.; Stoica, P.: System Identification. Hemel Hempstead (U.K) - Prentice-Hall, 1989.

[8] Söderström, T.; Stoica, P.; Trulsson, E.: Instrumen-tal variable methods for closed-loop systems. 10th IFAC World Congress - Munich (Germany), 1987, pp. 363-368.

[9] Gilson, M.; Van den Hof, P.M.J.: IV methods for closedloop system identification. 13th IFAC Symposium on System Identification - Rotterdam (The Netherlands), 2003, pp. 537-542.

[10] Söderström, T.; Ljung, L.; Gustavsson, I.: Identifiability conditions for linear multivariable systems operating under feedback. IEEE Trans. Automat. Contr., vol. 21, 1976, pp. 837-840.

[11] Ljung, L.: Information content in identification data from closed-loop operation. Proc. 32nd IEEE Conf. Decision and Control - San Antonio (Texas, USA), 1993, pp. 22482252.

[12] Van den Hof, P.M.J; Schrama, R.J.P.: An indirect method for transfer function estimation from closed loop data. Automatica, vol. 29, 1993, pp. 1523-1527.

[13] Vidyasagar, M.: Control System Synthesis - A Factorization Approach. Cambridge (MA) - MIT Press, 1985.

[14] Gustavsson, I.; Ljung, L.; Söderström, T.: Identification of processes in closed loop - identifiability and accuracy aspects. Automatica, vol. 13, 1977, pp. 59-75.

[15] Van den Hof, P.M.J.; de Callafon, R.A.: Multivariable closed-loop identification: from indirect identification to dual-Youla parameterization. Proc. 35th IEEE Conference on Decision and Control - Kobe (Japan), 1996, pp. 13971402.

[16] Ho, B.J.; Kalman, R.E.: Effective construction of linear state-variable models from input-output functions. Regelungstechnik, vol. 14, 1966, pp. 545-548.

[17] Vaes, D.; Souverijns, W.; De Cuyper, J.; Swevers, J.; Sas, P.: Decoupling feedback control for improved multivariable vibration test rig tracking. Proc. ISMA 2002 - Leuven (Belgium), 2002, pp. 525-534.

[18] MacFarlane, A.G.J.: Commutative controller: $A$ new technique for the design of multivariable control systems. Electronic letters, vol. 6, 1970, pp. 121-123.

[19] Owens, D.H.: Feedback and multivariable systems. London (U.K.) - Peter Peregrinus Ltd, 1978.

[20] Hung, S.Y.; MacFarlane, A.G.J.: Multivariable feedback: A quasi-classical approach. Berlin (Germany) - Springer Verlag, 1982.

[21] Bristol, E.H.: On a new measure of interaction for multivariable process control. IEEE Trans. on Automatic Control, vol. 11, 1966, pp. 133-134. 